\title{
Production induced subsidence and seismicity in the Groningen gas field - can it be managed?
}

\author{
J. A. de Waal, A. G. Muntendam-Bos, and J. P. A. Roest \\ State Supervision of Mines, The Hague, the Netherlands \\ Correspondence to: J. A. de Waal (j.a.dewaal@minez.nl) \\ Published: 12 November 2015
}

\begin{abstract}
Reliable prediction of the induced subsidence resulting from gas production is important for a near sea level country like the Netherlands. Without the protection of dunes, dikes and pumping, large parts of the country would be flooded. The predicted sea-level rise from global warming increases the challenge to design proper mitigation measures. Water management problems from gas production induced subsidence can be prevented if measures to counter its adverse effects are taken timely. This requires reliable subsidence predictions, which is a major challenge. Since the 1960's a number of large, multi-decade gas production projects were started in the Netherlands. Extensive, well-documented subsidence prediction and monitoring technologies were applied. Nevertheless predicted subsidence at the end of the Groningen field production period (for the centre of the bowl) went from $100 \mathrm{~cm}$ in 1971 to $77 \mathrm{~cm}$ in 1973 and then to $30 \mathrm{~cm}$ in 1977. In 1984 the prediction went up again to $65 \mathrm{~cm}$, down to $36 \mathrm{~cm}$ in 1990 and then via $38 \mathrm{~cm}$ (1995) and $42 \mathrm{~cm}$ (2005) to $47 \mathrm{~cm}$ in 2010 and $49 \mathrm{~cm}$ in 2013. Such changes can have large implications for the planning of water management measures.

Until 1991, when the first event was registered, production induced seismicity was not observed nor expected for the Groningen field. Thereafter the number of observed events rose from 5 to 10 per year during the 1990's to well over a hundred in 2013. The anticipated maximum likely magnitude rose from an initial value of less than 3.0 to a value of 3.3 in 1993 and then to 3.9 in 2006. The strongest tremor to date occurred near the village of Huizinge in August 2012. It had a magnitude of 3.6, caused significant damage and triggered the regulator into an independent investigation. Late 2012 it became clear that significantly larger magnitudes cannot be excluded and that values up to magnitude 5.0 cannot be ruled out. As a consequence the regulator advised early 2013 to lower Groningen gas production by as much and as fast as realistically possible. Before taking such a decision, the Minister of Economic Affairs requested further studies. The results became available early 2014 and led to the government decision to lower gas production in the earthquake prone central area of the field by $80 \%$ for the next three years. In addition further investigations and a program to strengthen houses and infrastructure were started.

Important lessons have been learned from the studies carried out to date. It is now realised that uncertainties in predicted subsidence and seismicity are much larger than previously recognised. Compaction, subsidence and seismicity are strongly interlinked and relate in a non-linear way to production and pressure drop. The latest studies by the operator suggest that seismic hazard in Groningen is largely determined by tremors with magnitudes between 4.5 and 5.0 even at an annual probability of occurrence of less than $1 \%$. And that subsidence in 2080 in the centre of the bowl could be anywhere between 50 and $70 \mathrm{~cm}$. Initial evaluations by the regulator indicate similar numbers and suggest that the present seismic risk is comparable to Dutch flooding risks.

Different models and parameters can be used to describe the subsidence and seismicity observed so far. The choice of compaction and seismicity models and their parameters has a large impact on the calculated future subsidence (rates), seismic activity and on the predicted response to changes in gas production. In addition there are considerable uncertainties in the ground motions resulting from an earthquake of a given magnitude and in the expected response of buildings and infrastructure. As a result uncertainties in subsidence and seismicity become very large for periods more than three to five years into the future. To counter this a control loop based on interactive modelling, measurements and repeated calibration will be used. Over the coming years, the effect of the
\end{abstract}


production reduction in the centre of the field on subsidence and seismicity will be studied in detail in an effort to improve understanding and thereby reduce prediction uncertainties. First indications are that the reduction has led to a drop in subsidence rate and seismicity within a period of a few months. This suggests that the system can be controlled and regulated. If this is the case, the integrated loop of predicting, monitoring and updating in combination with mitigation measures can be applied to keep subsidence (rate) and induced seismicity within limits. To be able to do so, the operator has extended the field-monitoring network. It now includes PS-InSAR and GPS stations for semi-permanent subsidence monitoring in addition to a traditional network of levelling benchmarks. For the seismic monitoring 60 shallow $(200 \mathrm{~m})$ borehole seismometers, $60+$ accelerometers and two permanent downhole seismic arrays at reservoir level will be added. Scenario's spanning the range of parameter and model uncertainties will be generated to calculate possible subsidence and seismicity outcomes. The probability of each scenario will be updated over time through confrontation with the measurements as they become available. At regular intervals the subsidence prediction and the seismic risk will be re-evaluated. Further mitigation measures, possibly including further production measures will need to be taken if probabilities indicate unacceptable risks.

\section{Introduction}

By end 2013 production induced subsidence above the centre of the Groningen gas field in the Netherlands amounted to some $33 \mathrm{~cm}$ with subsidence increasing at a rate of some 7-8 mm per year (van Thienen-Visser and Breunese, 2015a; Pijpers, 2014a). Such an amount of subsidence requires the design and implementation of proper mitigation measures in a near sea-level country like the Netherlands (de Waal et al., 2012). The country would largely flood without the presence of dykes and active pumping and the predicted sea-level rise from global warming increases the challenge.

As reported for a number of other oil and gas fields (Lee, 1979; Merle et al., 1976; de Waal and Smits, 1986; Hettema et al., 2002; Mallman and Zoback, 2007; Kosloff and Scott, 1980) subsidence rate in Groningen was initially significantly lower than predicted on the basis of laboratory rock-mechanical measurements carried out on samples taken from the reservoir. At a later stage the subsidence rate accelerated, coming closer to expected values and in line with the notion of "delayed subsidence" in (Hettema et al., 2002). While the subsidence accelerated, earthquakes started to occur. Over time these have increased in numbers and strength (Fig. 1). The strongest tremor so far with a magnitude of 3.6 occurred near the village of Huizinge in 2012, causing damage to thousands of homes and raising anxiety among those living in the area (Dost and Kraaijpoel, 2012). The mechanism behind the earthquakes is understood to be (differential) compaction at reservoir level reactivating existing faults that have become critically stressed as a result of production induced stress changes. Better understanding of the physics of reservoir compaction and fault reactivation is important to predict the further evolution of the Groningen subsidence and seismicity and to assess if and how the resulting seismic hazards and risks can be managed, e.g. through production measures such as changes in production rates, off-take pattern, nitrogen injection etc. and/or by executing a strengthening program for houses and infrastructure.
After discussing some general aspects of the Groningen field and its production history, the evolution of subsidence and seismicity since the start of production will be discussed in more detail with emphasis on the lessons that have been learned so far. Thereafter the recent developments will be discussed that followed the 2012 insight that risks from reservoir compaction induced seismicity in Groningen might be significantly higher then previously realised (MuntendamBos and de Waal, 2013).

\section{Field properties and production history}

The Groningen gas field was discovered in 1959 in the Lower Permian Rotliegend at a depth of some $3000 \mathrm{~m}$ by exploration well Slochteren-1 near the Dutch village of Kolham (van Hulten, 2009). The structure containing the Groningen reservoir is a NNW-SSE trending high formed by normal faulting during the Late Jurassic to early Cretaceous (Stäuble and Milius, 1970; Whaley, 2009). The high has an overall horst geometry, lying between the Eems Graben to the east and the Lauwerszee Trough to the west. The reservoir is covered by Late Permian Zechstein carbonate, anhydrite and halite evaporates which provide an excellent seal. The field covers an area of some $900 \mathrm{~km}^{2}$ and is located below a relatively densely populated area with some 250000 houses including several urban centres. The average thickness of the gas-bearing sandstone interval is some $100 \mathrm{~m}$. The field has excellent reservoir properties with porosity averaging around $17 \%$ and permeabilities in the hundreds of $\mathrm{mD}$ (Mijnlieff and Geluk, 2011; van Ojik et al., 2011). Some 1800 larger and smaller faults have been mapped based on the available 3-D seismic using ant tracking on the 3-D seismic cube (NAM, 2013).

History matching and pressure measurements in observation wells indicate all of the faults to be non-sealing with the exception of a number of larger faults at the field boundaries. The original volume of recoverable Groningen gas reserves is estimated at some $2800 \mathrm{BCM}(100 \mathrm{Tcf})$, which makes it 


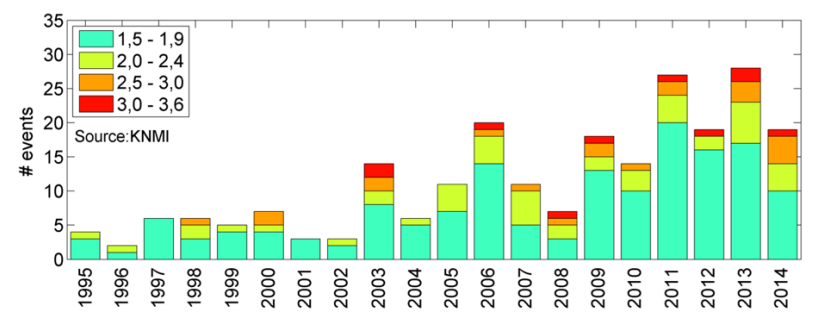

Figure 1. Groningen seismicity $(M>1.5)$ vs. time.

one of the larger gas fields worldwide. The gas is produced through more than 300 wells distributed over 22 production clusters. It contains slightly more then $15 \%$ nitrogen. Gas appliances in the Netherlands and surrounding countries are optimised for this. As a result Groningen gas cannot be replaced by gas with a different composition without enough time to replace these appliances economically. An option, which also works short-term, is to mix higher methane content gas from other sources with nitrogen. For a substantial replacement volume this is not a small task given the amounts of nitrogen required. Groningen production levels over time are shown in Fig. 2.

During the early seventies of the previous century the field was produced at high rates as it was anticipated that the value of the gas would be eroded away by cheap nuclear power. When it was realised that this would not happen, the production philosophy was changed drastically and Groningen became the regional swing producer. Preference was given to production from smaller onshore and offshore fields, the development of which is stimulated by tax measures (Small Fields Policy). The policy was so successful that the annual Groningen production dropped from values above 90 BCM in 1976 to as low as 20 BCM by 2000 . Thereafter production from the "Small Fields" started to decline with Groningen reaching a new annual high of 54 BCM in 2013. Presently more then two-third of the recoverable gas has been produced and first stage compression has been introduced. Over time the capacity of the Groningen field to act as the regional swing producer will decline and this role will be taken over gradually by large underground gas storage facilities.

\section{Subsidence}

\subsection{Early days}

Already during the early stages of field development it was realised that the gas production from the Groningen field could lead to a significant amount of surface subsidence. Detailed rock-mechanical measurement and modelling studies were executed (NAM, 1973) leading in 1973 to a predicted maximum subsidence of $100 \mathrm{~cm}$ at the end of field life, then expected around 2020. The prediction was based on an analytical linear elastic nucleus of strain model, supported by calculations with a linear elastic finite element numerical

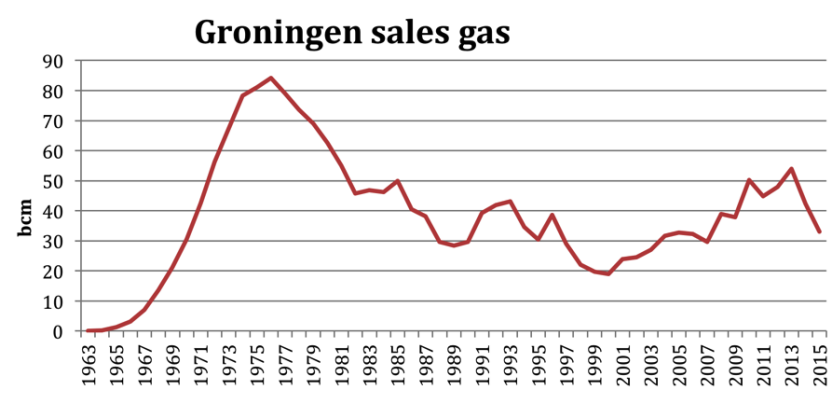

Figure 2. Groningen gas production (BCM/year) vs. time.

model. The use of a linear elastic model seemed justified by the results of a large number of zero pore pressure laboratory compaction measurements carried out on core samples taken from the reservoir. An extensive monitoring network was installed around the same time. It involved a significant extension of the existing local geodetic surface network, monitoring of near surface layer compaction (unrelated to gas production) and a number of dedicated down-hole reservoir compaction monitoring wells with radioactive bullets shot into the formation (NAM, 1973).

By 1973 it had become clear that both reservoir compaction and surface subsidence were occurring at a much lower rate then had been predicted. This remained the case also after applying a Biot correction factor to account for the effect of the field pore pressure, bringing the 1971 prediction down to $77 \mathrm{~cm}$ in 1973. In 1976 the predicted maximum subsidence at the end of field life was brought down to $30 \mathrm{~cm}$ by calibrating a linear elastic model against the 1977 levelling data (Schoonbeek, 1976). The reason for the large difference between the laboratory measured and the field observed rock compressibility was not clear. It was speculated to be caused by core damage from drilling, transport and laboratory procedures applied to the core samples prior to testing. A number of studies were started to investigate this and other potential explanations.

\subsection{The rate type compaction model}

The additional studies looked at the relation between reservoir compaction and surface subsidence, core disturbance, the validity of the effective stress concept, the in-situ stress state, possible previous deeper burial, pressure lag (between different permeability layers) and loading rate (de Waal, 1986). The study included an extensive re-analysis of the available data from Groningen and from other fields worldwide with significant subsidence, as well as rock-mechanical laboratory experiments on the effects of stress state, pore pressure, previous deeper burial, loading path, core disturbance and (changes in) loading rate. Based on the outcomes, the cause for the discrepancy in Groningen was postulated to be the large increase in loading rate that occurs in the reservoir at the start of depletion. Such an increase in load- 
ing rate cannot be easily simulated in laboratory experiments and even if this could be done, the rates at which laboratory experiments can be carried out remain much higher than those occurring in the field over geological times. Validating this explanation for field application is therefore problematic. The newly developed rate-type compaction model explained the difference between the initial field observed and the labderived compressibility for Groningen and explained the observed reduced and/or delayed subsidence above a number of other depletion-drive oil and gas reservoirs (de Waal, 1986; de Waal and Smits, 1988).

The physical explanation for the laboratory observed rate sensitivity was postulated to be time-dependent friction at the sliding mineral contact points (Dieterich, 1978, 1994) between (assemblies of cemented) grains or on microscopic fractures responsible for the non-elastic component in the compaction. Using a simple model incorporating the time dependent friction equation proposed by Dieterich, results in a differential equation popular in soil mechanics to describe the known rate dependent compaction behaviour of sands and soils at lower stress levels (Bjerrum, 1967; Kolymbas, 1977; Vermeer and Neher, 1999).

The use of the new model for predicting subsidence in Groningen was accepted in 1986. Subsidence at the end of field life was predicted to be around $65 \mathrm{~cm}$ with a one-sigma uncertainty of $10 \mathrm{~cm}$.

\subsection{Back to linear models}

Based on differences between the observed development of the subsidence above the Groningen field and predictions based on the rate type compaction model, the Groningen field operator in 1990 requested a review of the various subsidence predictions by two independent MIT advisors of high international standing (Toksöz and Walsh, 1990). The reviewers advised NAM to discount the prediction of Groningen subsidence on the basis of the rate type compaction model as they did not expect that loading or strain rate could have a significant effect on the deformation of the consolidated reservoir rock in the Groningen field. They advised the operator to return to the use of a linear elastic model calibrated against the field observed subsidence, leading to a new prediction for the ultimate maximum subsidence of $36 \mathrm{~cm}$. Further adjustments increased the prediction to $38 \mathrm{~cm}$ in 1995 and to $42 \mathrm{~cm}$ in 2005 to honour results of new surface levelling data. By 2005 it had become clear again that a linear model could not describe the field behaviour. The operator introduced a bi-linear compaction model in which the uniaxial compressibility increases after a given amount of pressure drop after which it stays at that higher value. The pivot point and the compressibility before and after the pivot point were fitted to honour new levelling survey measurements as they came in over time. Using this approach, the predicted maximum subsidence at the end of field life was increased to $47 \mathrm{~cm}$ in
2010 , including $2 \mathrm{~cm}$ of additional subsidence from the use of a lower gas abandonment pressure.

\subsection{Back to non-linear models}

By 2012 other Rotliegend gas reservoirs in the Netherlands showed continuing subsidence at a more or less constant gas pressure at the end of the production period. A bi-linear compaction model cannot explain such behaviour. For the time being NAM decided to switch to a time decay model, similar to a model proposed earlier by (Houtenbos, 2007) to describe the subsidence behaviour of compacting reservoirs. Mossop (Mossop, 2012) postulated a non-uniform heavy tailed permeability distribution resulting in a non-uniform pressure distribution within the bulk reservoir rock to be the explanation.

At the request of the regulator a new investigation into the physical background of the observed subsidence delays was commenced taking the permeability distribution explanation as only one of a number of possibilities. In addition salt flow, bottom and lateral aquifer inflow, intrinsic sandstone rate sensitivity, core disturbance, stress state and stress path are again being investigated.

One of the alternatives presently under consideration is a modified version of the rate-type compaction model abandoned for consolidated sandstones in 1990. The new formulation (Pruiksma et al., 2015) combines the features of the original rate type model with the soil mechanics isotach concept that enables transitions between different loading rates. The new isotach formulation combines a direct (linear elastic) strain component and a creep component, which elegantly explains the moderate loading rate dependence of the isotach compressibility. This way a number of limitations of the original rate type model have been resolved (de Waal et al., 2015), be it at the cost of an additional material property representing the linear elastic component of the deformation. The fit between predictions based on the modified isotach model and the measured subsidence in Groningen is better than that obtained with the time-decay model or the bi-linear model (van Thienen-Visser and Breunese, 2015).

The predicted impact of drastic changes in production rate during later stages of the production period is very different for the different compaction models. For the bi-linear model the predicted effect on compaction and subsidence is instantaneous, while for the isotach model the response is more gradual over a period of up to a year. The time-decay model predicts that it will take 5 to 10 years for the rock to respond to significant changes in production rate.

\section{Induced seismicity}

\subsection{History}

Until 1991 no induced seismicity was registered in the Groningen field, nor was it expected. The independent study 
by MIT experts (Toksöz and Walsh, 1990) estimated the probability of an induced seismic event with a magnitude above 3.0 at less then $10 \%$ for the next 50 years. If such an event would occur at all, they expected it to happen on the sealing faults at the field edges, not in the field centre. History proved different. For a number of other fields in the Netherlands induced seismicity had been linked to gas production a few years earlier (BOA, 1993). While subsidence in Groningen was accelerating, induced seismicity started to occur. The first production-induced earthquake with a local magnitude $M_{\mathrm{L}}$ of 2.4 was recorded at Middelstum in 1991. The frequency and magnitude of the events thereafter continued to increase over time as shown in Fig. 1. The local seismic network was upgraded a number or times and is complete for magnitudes above 1.5 since 1995 . To date, close to a thousand gas production induced earthquakes have been registered in Groningen. Most events have been of a small magnitude $\left(M_{\mathrm{L}}<1.5\right)$, while by mid 2015 some 250 earthquakes had magnitudes $M_{\mathrm{L}} \geq 1.5$. In contrast to early expectation, the tremors do not occur on the sealing faults at the field boundaries. They occur mainly in more central areas where cumulative compaction and the density of faults with unfavourable offsets are highest. The mechanism behind the earthquakes is now generally considered to be (differential) compaction at reservoir level reactivating offset faults as originally proposed by (Roest and Kuilman, 1994).

Initially doubts on the relation between gas production and observed seismicity continued, even after an official investigation in 1993 (known as the BOA study) concluded that the two were linked. Based on an analysis of the seismicity, initial estimates were made of the maximum probable magnitude that could be expected to occur. The 1993 BOA study came to an initial estimated value of 3.3. KNMI later increased this estimate to 3.3-3.5 in 1995 (de Crook et al., 1995), to 3.7 in 2006 (de Crook et al., 1998) and then to 3.9 in 2006 (van Eck et al., 2006). In (de Lange et al., 2011) it is estimated that induced seismic events with magnitudes below 3.9 would not result in severe structural damage to buildings and hence the associated risk was deemed acceptable until things changed by end 2012. As of 2008 State Supervision of Mines (the Dutch regulator) became more and more concerned about the increasing frequency of the induced seismicity and the increasing magnitudes. TNO was asked to carry out a study into possible explanations (MuntendamBos, 2009). The conclusions and recommendations of this study led to a request to the operator by end 2009 for further research into possible mechanisms and feasible remedies, the results of which needed to be included in the required 2013 update of the Groningen winningsplan.

\subsection{New insights}

By mid 2012 the larger than predicted annual frequency of earthquakes with a magnitude equal or above 3.0 further increased the concerns of State Supervision of Mines (SSM) and intensified discussions with the operator. On 16 August 2012 an induced seismic event with a magnitude of 3.6 occurred near the village of Huizinge. It was the highest magnitude event registered in Groningen to that date, causing damage to thousands of homes and raising anxiety among those living on or near the field (Dost and Kraaijpoel, 2012). It triggered SSM into commencing its own investigation, including a new statistical analysis of all the available Groningen seismicity data (Muntendam-Bos and de Waal, 2013). The results were worrying. The SSM analysis indicated a continuous and systematic increase in the number of events and their magnitude (Fig. 3). The same figure suggests that smaller magnitude events might well have started earlier, without being detected given the limitations of the local seismic network at the time. The SSM analysis also showed that an upper magnitude bound - generally deemed to be 3.9 - could not be derived from a statistical analysis of the Groningen seismicity while other methodologies to arrive at such an upper estimate could not exclude values up to at least a magnitude 5 (Muntendam-Bos and de Waal, 2013). The results were confirmed by studies carried out by the operator (NAM, 2013, Bourne et al., 2014). In addition the SSM analysis suggested that increases and decreases in the annual number of seismic events could be linked to increases and decreases in the annual gas production rate with a delay of 6 to 12 months (Fig. 4). Based on the results of its investigation, SSM judged the seismic risk in Groningen as "high" and advised early January 2013 to reduce gas production by as much and as fast as realistically possible.

The SSM advice was followed by a year of concerted data acquisition and further studies, while production continued and reached its highest annual level in nearly 20 years (54 BCM). The results of the studies became available by end 2013 and suggested that the local seismic activity rate in Groningen increases exponentially with cumulative reservoir compaction (NAM, 2013). If correct it implies that production reductions in areas with large compaction are most effective to reduce future seismicity. Based on this insight the earlier SSM advice became more focussed: stop gas production in the central area of the Groningen field - where the largest amount of reservoir compaction takes place - for at least three years (Staatstoezicht, 2014). The ministerial decision, based on this advice, was to reduce the production in the centre of the field by $80 \%$. It was implemented on 17 January 2014. Initially the operator was allowed to increase production in areas outside the centre of the field to partly compensate for the production reduction in the centre. These production increases were capped in December 2014 after early observations suggested they resulted in increases in seismicity in these areas outside the field centre. It was realised from the start that the implemented production measures would probably only work temporarily (if at all) as pressure depletion in the centre of the field will resume after a few years given the continued production elsewhere. The large-scale data acquisition and study program was therefore 


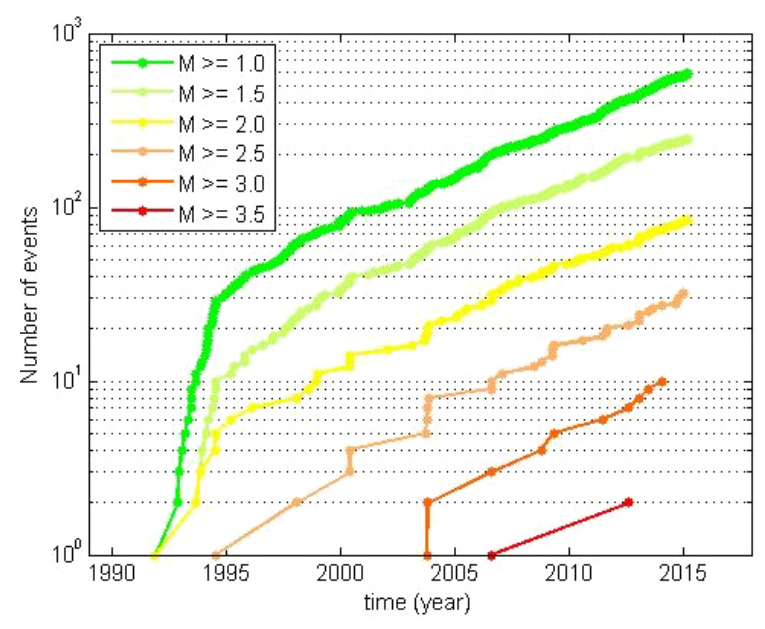

Figure 3. SSM analysis of the Groningen induced seismicity.

continued and extended and a program to strengthen houses and infrastructure was started.

\section{Recent developments}

\subsection{Field response}

The main question related to the January 2014 production measures were how effective they would be to reduce the seismicity and on what time scale. Time is required for the pressure signal resulting from the shut-in at the central clusters to spread through the reservoir. Given the Groningen reservoir properties it takes some three months for that signal to reach a distance of $3 \mathrm{~km}$ (van Thienen-Visser and Breunese, 2015). As (differential) compaction is the engine behind the induced seismicity, the time scale on which compaction responds to stress changes is a second major factor. The time decay model predicts a typical response time of five to seven years. Linear and bi-linear compaction models predict an instant response. The rate type isotach model predicts part of the response to be immediate and part of it to happen over the next 6 to 12 months. In addition there is a delay from the time it takes for the pressure effect from the production reduction to diffuse from the wells into the reservoir.

Another factor influencing the response is the seismological model linking seismicity to compaction. On the one hand it can cause additional delays as a result of rate and state friction on the fault surfaces where the seismicity is generated. On the other hand the postulated exponential rise of seismic activity rate in combination with compaction creep would dampen the response significantly. Given the epistemic uncertainties around the compaction model and the seismological model in combination with the absence of empirical data, it was very uncertain how the seismicity would respond and a "wait and see" approach was taken. To be able to do so, the operator has extended the field monitor-

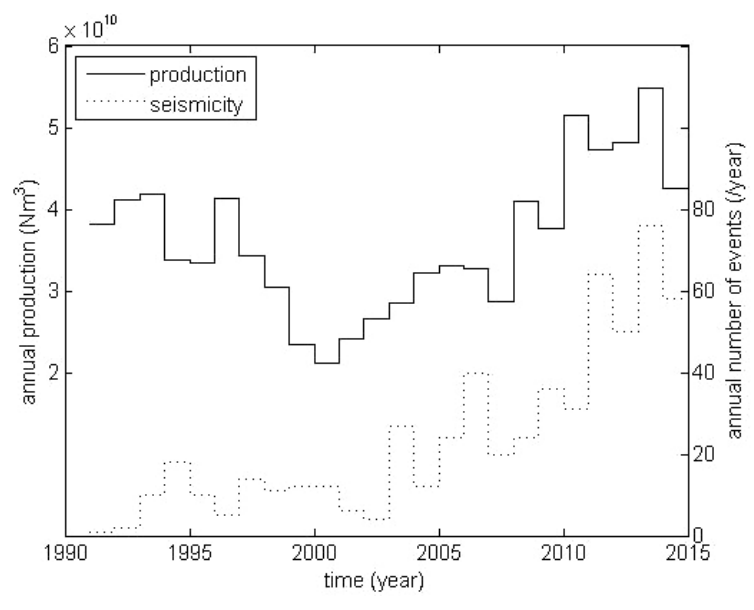

Figure 4. Groningen annual production and annual induced seismicity $(M>1.0)$.

ing to include PS-InSAR and a network of differential GPS stations for semi-permanent subsidence monitoring. For the seismic monitoring 60 shallow $(200 \mathrm{~m})$ borehole seismometers, $60+$ accelerometers and two temporally installed downhole seismic arrays at reservoir level in the centre of the field are now in place. The latter will be replaced by permanent installations shortly.

Conclusions on the seismic response to the reduced production in the central area of the field within a period of a year are a challenge given the statistical character of the seismicity and the challenge to accurately measure compaction rate changes over relatively short periods. Nevertheless results to date look promising. A double-double difference analysis of the GPS stations in the centre and those at the edge of the field carried out by Statistics Netherlands (Pijpers, 2014a) shows a clear break in subsidence rate around April 2014 as shown in Fig. 5. Seismic event density maps over the Groningen field for three consecutive periods of a year are discussed in (van Thienen-Visser, 2015b). A clear change in the pattern of seismic events is visible during the third period with seismicity reducing significantly in the central area of the field after April 2014 (Fig. 6). An independent second study by Statistics Netherlands (Pijpers, 2014b) confirms the statistical significance of the changes in seismic activity. Although not yet scientifically conclusive at a $99 \%$ confidence level these results support decision making on remediating measures to reduce future seismic risk as they suggest that the seismicity can be controlled and regulated at relatively short notice.

\subsection{Risk}

Early 2013 SSM estimated the seismic risk level in Groningen as "high", based on the realisation that events with a magnitude well above 3.9 could not be excluded. Based on SSM's analysis an assumed upper magnitude limit of 5.0 re- 


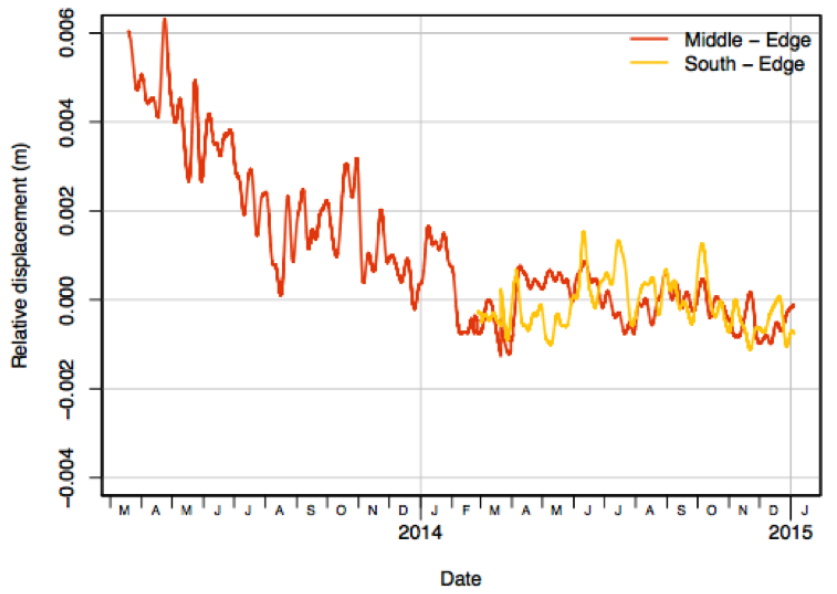

Figure 5. Analyses of GPS data showing break in subsidence rate around April 2014.

sulted in an annual probability of $3 \%$ for an earthquake with a magnitude 4.5 or higher, a level at which serious damage cannot be excluded as houses in the Netherlands are not built to sustain seismic ground motions. By end 2013 a more detailed risk analysis was made for the central area of the field (Staatstoezicht, 2013; Muntendam et al., 2013). Based on a probabilistic analysis of the ground motions that can occur and taking into account the fragility of the local housing stock, data made available by the operator was translated into annual LPR (local personal risk) numbers and a Group risk $F-N$ (frequency-number) plot. Results show that the seismic risk levels in Groningen are considerable and comparable to the highest flooding risk levels in the Netherlands (Fig. 7). Subsequent work by a dedicated impact assessment expert committee during 2014 estimated the number of houses in Groningen exceeding an LPR of 10-4 to be between 40000 and 90000 (Stuurgroep NPR, 2015). Supporting a widely accepted minimum LPR level of 10-5, the committee recommends strengthening the housing stock to 10-4, assuming actual LPR levels will come down when more refined and less conservative calculations become available. A final norm needs to be developed taking into account acceptable seismic risk, security of supply issues and financial consequences.

\subsection{Measurement and control loop}

Target is the cyclic development of a well organised risk management plan with clear objectives, well defined risk norms and control measures with proven effectiveness. To start, scenario's spanning the range of parameter and model uncertainties will be generated to calculate possible subsidence and seismicity outcomes. The probability of each scenario will be updated over time through confrontation with measurements as they become available. At regular intervals the subsidence prediction and the seismic risk will be reevaluated. Further mitigation measures, possibly including

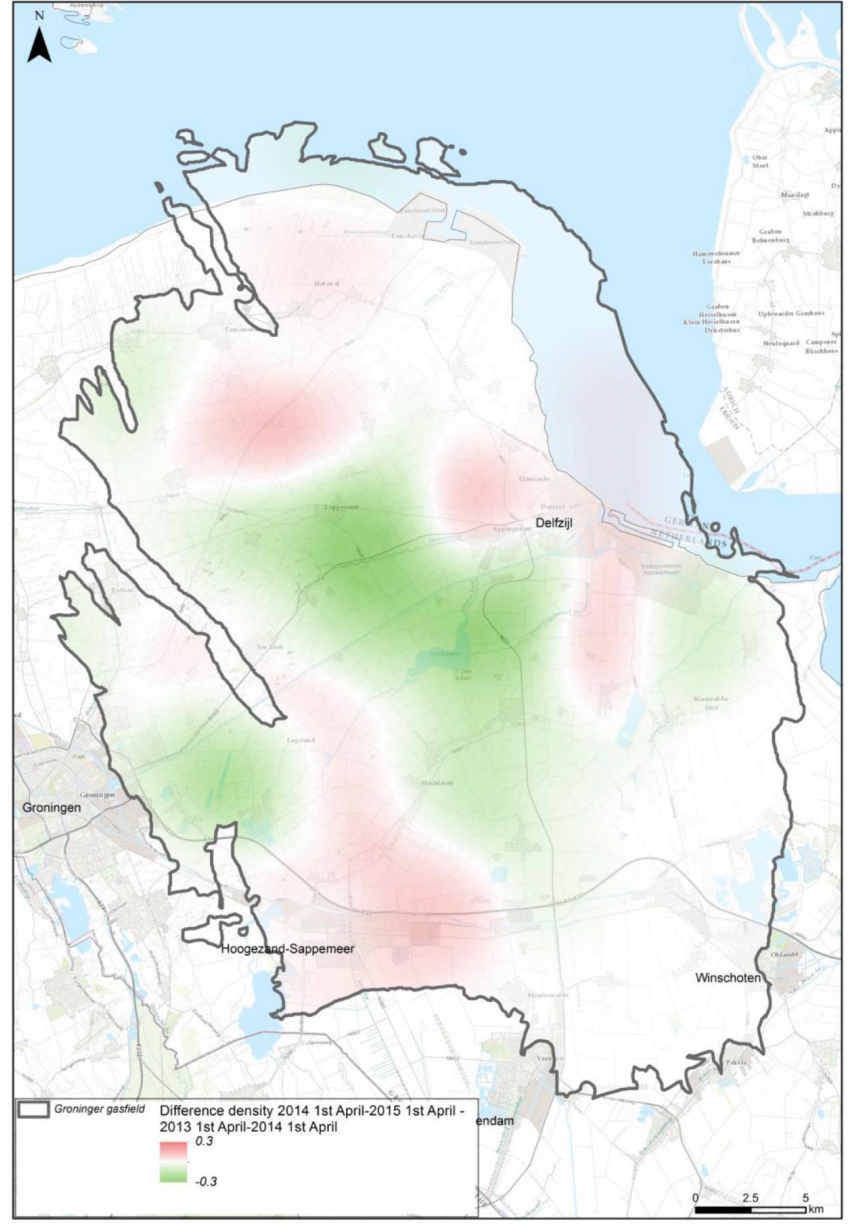

Figure 6. Increases and decreases in seismic event density after production reductions (from van Thienen-Visser et al, 2015b).

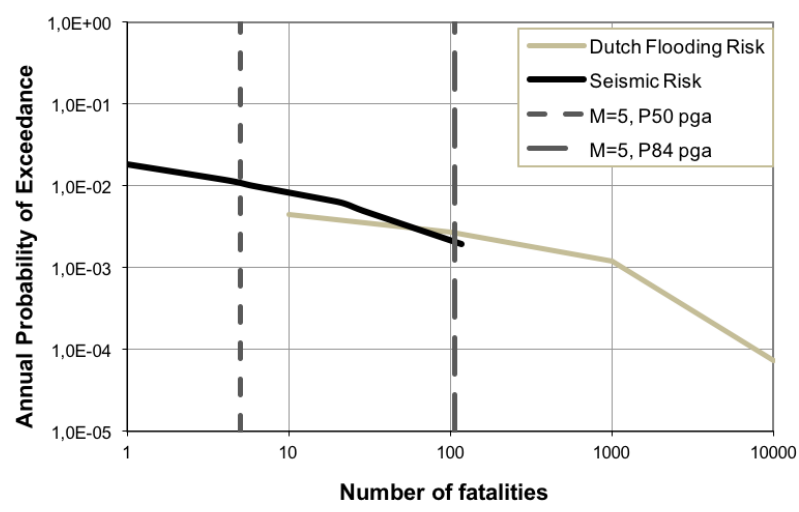

Figure 7. Calculated seismic Group Risk Loppersum area (from Muntendam et al., 2015).

further production measures and further building strengthening measures will need to be taken if probabilities indicate unacceptable risks. A possible framework for a measurement and control loop enabling adjustments when seismicity met- 
rics indicate a risk of exceeding acceptable risk is shown in Fig. 8. To apply the concept it needs to be part of a "Seismic Risk Management Protocol" that should contain the following elements:

1. agreed metrics to express the seismic risk;

2. a norm for the amount of seismic risk considered acceptable considering societal issues, security of supply and financial consequences, translated into an enforceable, operational criterion;

3. a probabilistic assessment of the seismic risk (taking into account all uncertainties):

a. as a function of location and time;

b. under different production scenarios;

c. taking into account the effect of strengthening programs;

4. an agreed procedure, including regular analysis of proper signal parameters like GPS subsidence rate and seismic event density.to update the predicted probabilistic seismic risk as new data is gathered;

5. a measurement plan;

6. agreed 'SMART" measures (production/pressuremaintenance/strengthening) to adjust the seismic risk using a multi-objective optimisation (minimising seismic risk, while maximising security of supply and state income);

7. an independent audit system to ensure compliance and to verify the technical integrity of the underlying work.

\section{On-going and future work}

The on-going large study and data acquisition effort by the operator is continued and extended to arrive at a better understanding of the gas production induced reservoir compaction, surface subsidence and induced seismicity in Groningen. Aim is to reduce the large epistemic and aleatory uncertainties, to arrive at better monitoring and prediction of subsidence and seismicity, to better estimate seismic risk as a function of location and time and to assess the possibility to implement a measurement and control loop to contain seismic risk.

Regular surface levelling campaigns continue, complemented by semi-continuous PS-InSAR measurements and a network of permanent GPS stations distributed over the field. The existing network of shallow seismic monitoring wells is being upgraded to some 60 deep (100-200 m) boreholes spread over the field. The expectation is that this results in a completeness level of 0.5 by end 2015 , leading to a tenfold increase in the detectable number or seismic events and a threefold reduction of the aleatory uncertainty in the seismicity activity level. In addition some $60+$ accelerometers and two permanent downhole seismic arrays at reservoir level are being installed. The accelerometers will help to reduce the uncertainties in the GMPE (ground motion prediction equation) relating earthquake magnitude to surface acceleration.

Extensive statistical (trend) analyses will be carried out to investigate the effects of compaction (rate) and compaction distribution on the spatial and temporal changes in seismic activity rate and $b$ value (determining the ratio between weak and strong events). A similar analysis will be carried out to investigate the effect of production rate and production distribution. The improved detection limit of the extended seismic network is expected to be very beneficial for this type of work. The outcomes of the various analyses will be used to validate the present (activity rate) seismological model developed by the operator and to introduce model improvements if necessary. Potential examples are the incorporation of (nonlinear) compaction rate dependence and the incorporation of a critical stressing rate above which the seismic activity rate increases rapidly (Llenos et al., 2009; Toda et al., 2002).

Better static and dynamic subsurface models are being constructed to model reservoir property distributions (e.g. porosity, permeability, faults, compressibility). An example is the latest structural model for which more than 1800 faults have been mapped at reservoir level using ant tracking on the 3-D seismic cube (NAM, 2013). Another example is the detailed characterisation of the near surface layers to a depth of several hundred meters, important for seismic wave attenuation calculations. The subsurface models will be updated as new data becomes available while the operator and TNO have started on inversion of the surface subsidence data to better determine the amount and distribution of the downhole reservoir compaction.

The operator is combining the static, dynamic and geomechanical reservoir models with a seismological model, a ground motion predication equation, a database of building types and locations and with fragility curves for the various building types to arrive at probabilistic (Monte Carlo) predictions of seismic hazard and seismic risk under a number of different production scenarios and housing reinforcement programs (Bourne et al., 2014).

\section{Lessons}

A number of important lessons can be learnt from the history of subsidence and induced seismicity in Groningen. First it is clear that epistemic uncertainties were largely underestimated from the start and during a long period thereafter. This is illustrated by the large changes over time in the predicted maximum subsidence at the end of field life in the centre of the Groningen field. It illustrates that initial uncertainties, prior to the start of production, are perhaps as large as a fac- 


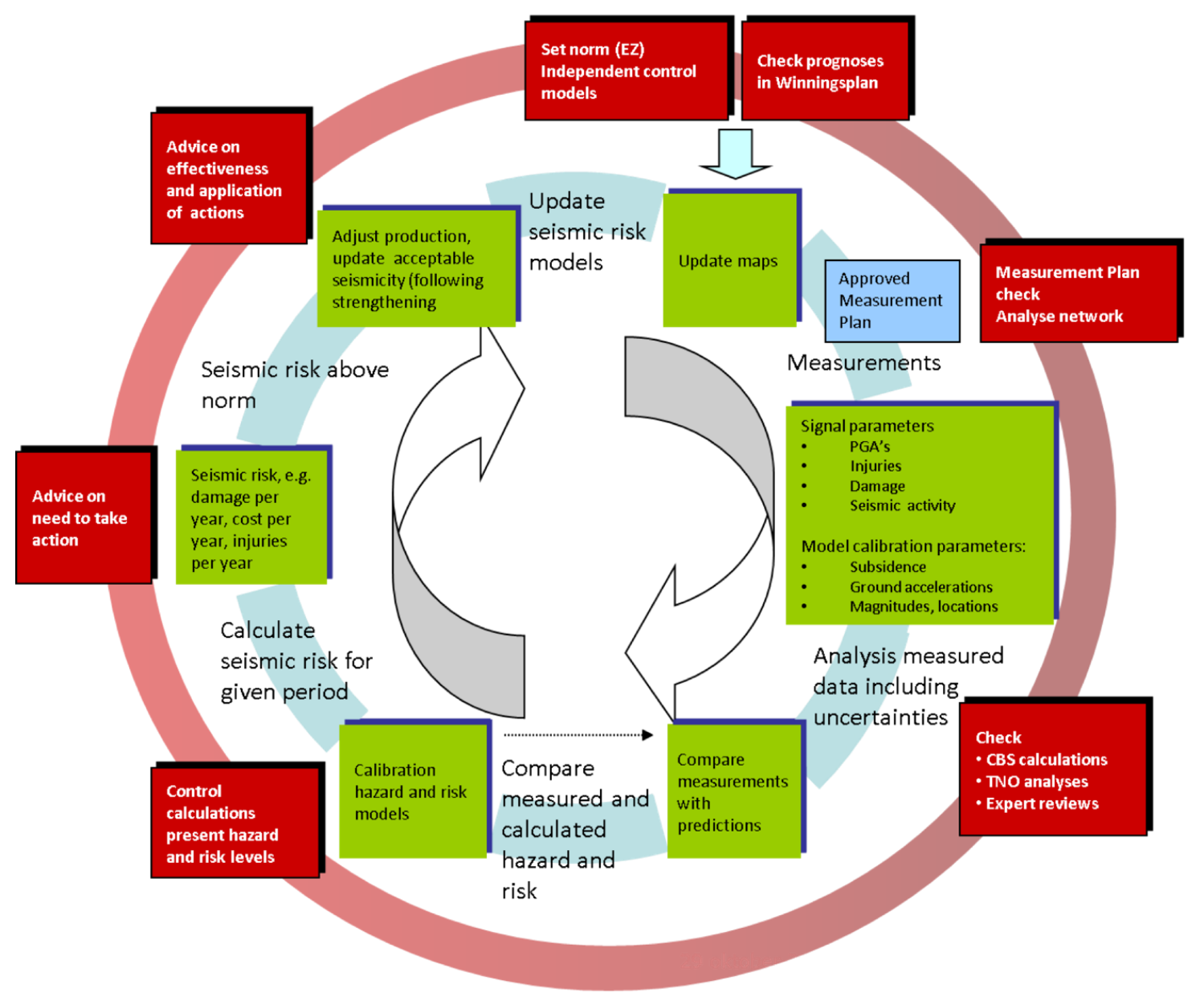

Figure 8. A possible seismic risk "measurement and control" loop.

tor of two (up or down) relative to the predicted expectation case. This has meanwhile been confirmed for a number of other fields in the Netherlands (de Waal et al., 2012). Major potential contributors are uncertainties in subsurface models, unknown influx of bottom and lateral aquifers, core damage, non-linear rock compressibility, the difference in loading rate between laboratory and field, the very large change in loading rate at the start of production, the in-situ stress state, reservoir burial history, salt flow, the relation between subsidence and compaction etc. Rather than predicting a single number it is therefore much better to provide a range of possible outcomes, only reducing the range when certain scenarios become too unlikely given field measurements (Nepveu et al., 2010). And to keep the range of possible outcomes, as it narrows over time, in line with the range that the area can sustain e.g. by timely taking appropriate mitigation measures where and when required.

Secondly it seems that non-linear compaction is the norm rather than the exception with the rate type isotach compaction model as a plausible explanation for the transition zone that follows the large increase in loading rate at the start of the production period. The effects are well known from Soil Mechanics where a long time geological loading manifests itself as an apparent over consolidation from previous deeper burial (which it is not). This also implies that a certain degree of additional subsidence can be expected as a result of creep after the production period has ended. Subsidence and seismicity response time following the significant production adjustment in January 2014 seem in the order of a couple of months. Although not rigidly proven at a $95 \%$ confidence level, it does seem to favour the rate type isotach model over the time decay model which uses a single 5-7 year response time to explain the initial subsidence delay after the start of production.

Also for induced seismicity, history proved very different from the original expectations. At the start of the production period induced seismicity was not expected and when it happened it took many years before its linkage to the gas production was widely accepted, an good illustration of the strength of paradigms. Contrary too initial expectation the seismicity has focussed in the central area of the field where the faults are not sealing. Also initial expectations on the ability to pre- 
dict an upper bound on the likely magnitude to occur proved wrong and it is now realised that there is significant seismic risk that needs to be contained through a measurement and control loop including production measures and a housing and infra-structure strengthening programs.

The response time of a few months of subsidence rate and seismic activity rate to the production measures that have been taken suggests that the risk can be managed by adjusting production rates. To sustain a reduced seismicity level over longer periods of time, field-wide production measures will need to be taken as pressure decline in the centre of the field will re-start within a few years given the continued production from production clusters outside of the centre of the field. It is still unclear if production reductions will only smear the risk out over time (film-rate effect) or if real reductions in the total number of earthquakes can be expected. As a minimum, production reduction will buy time for further study and to strengthen buildings and infrastructure.

Acknowledgements. The authors want to thank the management of State Supervision of Mines for permission to publish this paper. We also thank staff at TNO, KNMI, CBS (Statistics Netherlands) and NAM for stimulating discussions and support although they may not agree with all of the interpretations and conclusions of this paper. We are particularly grateful for the contributions and support provided by Karin van Thienen-Visser and Jaap Breunese at TNO and by Jan van Herk at State Supervision of Mines.

\section{References}

Bjerrum, L.: Engineering geology of Norwegian normally consolidated marine clays as related to settlements of buildings, in: Geotechnique, Seventh Rankine Lecture 17, 81-118, 1967.

BOA (Begeleidingscommissie Onderzoek Aardbevingen): Eindrapport multidisciplinair onderzoek naar de relatie tussen gaswinning en aardbevingen in Noord-Nederland, Koninklijk Nederlands Meteorologisch Instituut, Afdeling Seismologie, De Bilt, 76 pp., 1993 (in Dutch).

Bourne, S. J., Oates, S. J., Elk, J. van, and Doornhof, D.: A seismological model for earthquakes induced by fluid extraction from a subsurface reservoir, J. Geophys. Res. Solid Earth, 119, 89919015, doi:10.1002/2014JB011663, 2014.

de Crook, Th., Dost, B., and Haak, H. W.: Analyse van het seismische risico in Noord Nederland, KNMI TR-168, de Bilt, 30 pp., 1995 (in Dutch).

de Crook, Th., Dost, B., and Haak, H. W.: Seismisch risico in Noord-Nederland, KNMI, 1998 (in Dutch).

de Lange, G., Oostrom, N. G. C. van, Dortland, S., Borsje, H., and de Richemont, S. A. J.: Gebouwschade Loppersum, Deltaris 1202097-000, 84 pp., 2011 (in Dutch).

de Waal, J. A.: On the rate type compaction behaviour of sandstone reservoir rock, PhD dissertation, Delft University of Technology, 166 pp., 1986.

de Waal, J. A. and Smits, R. M. M.: Prediction of reservoir compaction and surface subsidence: field application of a new model, SPE Formation Evaluation 3, 347-356, 1988. de Waal, J. A., Roest, J. P. A., Fokker, P. A., Kroon, I. C., Breunese, J. N., Muntendam-Bos, A. G., Oost, A. P., and van Wirdum, G.: The effective subsidence capacity concept: How to assure that subsidence in the Wadden Sea remains within defined limits, in: Geologie en Mijnbouw Neth. J. of Geoscience, 91, 385-399, 2012.

de Waal, J. A., van Thienen-Visser, K., and Pruiksma, J. P.: Rate type isotach compaction of consolidated sandstone, 49th US Rock mechanics/Geomechanics symposium (ARMA), San Francisco, 28 June-1 July, ARMA 15-436, 2015.

Dieterich, J. H.: Time-dependent friction and the mechanics of stick-slip, Pageoph., 116, 790-806, 1978.

Dieterich, J. H.: A constitutive law for rate of earthquake production and its application to earthquake clustering, J. Geoph. Res. 99, 2601-2618, 1994.

Dost, B. and Kraaijpoel, D.: The August 16, 2012 earthquake near Huizinge (Groningen), KNMI publication TR 16/1/2013, 26, 2012.

Hettema, M., Papamichos, E., and Schutjens, P.: Subsidence delay: field observations and analysis, Oil and Gas Science and Technology, in: Revue dIFP, Energies Nouvelles, 57, 443-458, 2002.

Houtenbos, A. P. E. M.: Subsidence and gas production: an empirical relation, SubsvsProdFinal.doc, 1-8, available at: http:// bodemdaling.houtenbos.org/resources (last access: 5 November 2015), 2007.

Kolymbas, D.: A rate-dependent constitutive equation for soils, Mech. R. Comms., 4, 367-372, 1977.

Kosloff, D. and Scott, R. F.: Finite element simulation of Wilmington oil field subsidence: II Nonlinear Modelling, Tectonoph., 70, 59-183, 1980.

Lee, L. L.: Subsidence earthquake at a California oil field, in: Evaluation and prediction of subsidence, edited by: Saxena, S. K., New York, ASCE, 549-564, 1979.

Llenos, A. L., McGuire, J. J., and Ogata, Y.: Modelling seismic swarms triggered by aseismic transients, Earth Planet. Sci. Lett., 281, 59-69, 2009.

Mallman, E. P. and Zoback, M. D.: Subsidence in the Louisiana coastal zone due to hydrocarbon production, J. of Coastal Res. SI, 50, 443-449, 2007.

Merle, H., Kentie, C., van Opstal, G., and Schneider, G.: The Bachaquero study - a composite analysis of the behavior of a compaction drive/solution gas drive reservoir, J. of Petr. Techn., 27, 1107-1115, 1976.

Mijnlieff, H. F. and Geluk, M.: Palaeotopography-governed sediment distribution-a new predictive model for the Permian Upper Rotliegend in the Dutch sector of the Southern Permian Basin, in: The Permian Rotliegend of the Netherlands, edited by: Grötsch, J. and Gaupp, R., SEPM Special Publication No. 98, 147-159, ISBN: 978-1-56576-300-5, 2011.

Mossop, A.: An explanation for anomalous time dependent subsidence, in: Proc. 46th US Rock Mech. Symp., 24-27 June, Chicago, 60-68, 2012.

Muntendam-Bos, A. G.: Geïnduceerde trillingen in of nabij het Groningen gasveld, een aanzet tot een geomechanische verklaring, available at: http://www.nlog.nl/nl/reserves/ reserves/AGE09-10100_RapportAardtrillingenGroningenveld_ PUBLIEK_NLOG.pdf (last access: 5 November 2015), 2009 (in Dutch). 
Muntendam-Bos, A. G. and de Waal, J. A.: Reassessment of the probability of higher magnitude earthquakes in the Groningen gas field: technical report, available at: http://www.researchgate. net/publication/271764011_Reassessment_of_the_probability_ of_higher_magnitude_earthquakes_in_the_Groningen_gas_field (last access: 5 November 2015), February 2013.

Muntendam-Bos, A. G., Roest, J. P. A., and de Waal, J. A.: A guideline for gas production induced seismic risk, The Leading Edge, special issue Injection Induced Seismicity, 672-677, 2015.

NAM: The analysis of surface subsidence resulting from gas production in the Groningen area, the Netherlands, Trans. Royal Dutch Soc. of Geol. and Mining Eng., edited by: Nederlandse Aardolie Maatschappij B. V., 28, 1973.

NAM: Wijziging winningsplan Groningen 2013, inclusief technische bijlage Groningen winningsplan 2013, Versie 29, November 2013 (partly in Dutch).

Nepveu, M., Kroon, I. C., and Fokker, P. A.: Hoisting a Red Flag: An Early Warning System for Exceeding Subsidence Limits, Math Geosci. 42, 187-198, doi:10.1007s11004-009-9252-2, 2010.

Pijpers, F.: Phase0 report1, Significance of trend changes in ground subsidence in Groningen, Statistics Netherlands Scientific paper, CBS, 14 pp., 2014a.

Pijpers, F.: Phase0 report2, Significance of trend changes in tremor rates in Groningen, Statistics Netherlands Scientific paper, CBS, 18 pp., 2014 b.

Pruiksma, J. P., Breunese, J. N., van Thienen-Visser, K., and de Waal, J. A.: Isotach formulation of the rate type compaction model for sandstone, Int. J. Rock Mech. Min., 78, 127-132, doi:10.1016/j.ijrmms.2015.06.002, 2015.

Roest, J. P. A. and Kuilman, W.: Geomechanical Analysis of Small Earthquakes at the Eleveld gas Reservoir, in: Proc. Eurock '94, Balkema, Rotterdam, 573-580, 1994.

Schoonbeek, J. B.: Land subsidence as a result of natural gas extraction in the province of Groningen, SPE European Spring Meeting, 8-9 April, Amsterdam, the Netherlands, 20 pp., SPE 5751, 1976.

Staatstoezicht op de Mijnen: Risico Analyse Aardgasbevingen Groningen, available at: https://www.sodm.nl/sites/default/files/ redactie/RisicoanalyseaardgasbevingenGroningen.pdf (last access: 5 November 2015), Den Haag, December 2013 (in Dutch).

Staatstoezicht op de Mijnen: Advies winningsplan 2013/Meeten Monitoringplan NAM Groningen gasveld, available at: https://www.sodm.nl/sites/default/files/redactie/ AdviesSodMwinningsplanGroningen2013.pdf (last access: 5 November 2015), 2014 (in Dutch).
Stäuble, A. J. and Milius, G.: Geology of the Groningen gas field, Netherlands Am. Ass. Petrol. Geol., Mem., 14, 359-369, 1970.

Stuurgroep NPR: Impact assessment Nederlandse Praktijk Richtlijn aardbevingsbestendig bouwen, 8 January 2015 (in Dutch).

TNO: Toetsing van de bodemdalingsprognoses en seismische hazard ten gevolge van gaswinning van het Groningen veld, R11953, Eindrapport, Utrecht, 218 pp., 2013 (in Dutch).

Toda, S., Stein, R. S., and Sagiya, T.: Evidence from the AD 2000 Izu islands swarm that stressing rate governs seismicity, Nature, 418, 58-61, 2002.

Toksöz, M. N. and Walsh, J. B.: An evaluation of the subsidence program directed by Nederlandse Aardolie Maatschappij, NAM EP90-20043, 51 pp., 1990.

van Eck, T., Goutbeek, F. H., Haak, H. W., and Dost, B.: Seismic hazard due to small-magnitude, shallow-source, induced earthquakes in the Netherlands, Eng. Geol., 87, 105-121, doi:10.1016/j.enggeo.2006.06.005, 2006.

van Hulten, F. F. N.: Brief history of petroleum exploration in the Netherlands, in: Symposium fifty years of petroleum exploration in the Netherlands after the Groningen discovery, EBN, TNO, Geo-Energy and PGK, 15-16 January 2009, Utrecht, 2009.

van Ojik, K., Böhm, A. R., Cremer, H., Geluk, M. C., De Jong, M. G. G., Mijnlieff, H. F., and Djin Nio, S.: The rationale for an integrated stratigraphic framework of the Upper Rotliegend depositional system, in: The Permian Rotliegend of the Netherlands, edited by: Grötsch, J. and Gaupp, R., SEPM Special Publication No. 98, 37-48, ISBN: 978-1-56576-300-5, 2011.

van Thienen-Visser, K. and Breunese, J.: Induced seismicity of the Groningen gas field: history and recent developments, The Leading Edge, special issue Injection Induced Seismicity, 665-671, 2015a.

van Thienen-Visser, K., Fokker, P., Nepveu, M., Sijacic, D., Hettelaar, J., and van Kempen, B.: Recent developments of the seismicity of the Groningen field in 2015, TNO R10755, 2015b.

Vermeer, P. and Neher, H.: A soft soil model that accounts for creep, in: Beyond 2000 in computational geotechnics-10 years of Plaxis international, Balkema, Rotterdam, ISBN: 905809040 X, 1999.

Whaley, J.: The Groningen gasfield, GEO ExPro Magazine, Vol. 6-4, available at: http://www.geoexpro.com/articles/2009/04/ the-groningen-gas-field (last access: 5 November 2015), 2009. 